\title{
Serum selenium concentration associated with risk of
}

\section{cancer}

\author{
J RINGSTAD,* B K JACOBSEN,* S TRETLI, $\dagger$ Y THOMASSEN $\ddagger$
}

From the * Institute of Community Medicine, University of Tromso, $\dagger$ The Cancer Registry of Norway, Oslo, and the $\ddagger$ Institute of Occupational Health, Oslo, Norway

SUMMARY The association between serum selenium concentration and risk of cancer was studied in a nested case control study. Case control pairs came from a population of 9364 people examined in 1979. During the six year follow up, 60 men and women aged between 20-54 at the time of blood sampling, who had been free of malignant disease, developed cancer. The mean serum selenium concentration of $1.56 \mu \mathrm{mol} / 1(123.2 \mu \mathrm{g} / \mathrm{l})$ in patients was not significantly different from that in controls $(1.63 \mu \mathrm{mol} / 1(128.7 \mu \mathrm{g} / \mathrm{l}))$. The difference in mean selenium concentration was largest and most significant for haematological malignancies alone. The difference in selenium concentrations in cases of fatal cancer compared with controls was significant $(p<0.01)$.

The risk of developing adenocarcinomas does not seem to be influenced by serum selenium concentration.

In recent years malignant morbidity and mortality have been observed to be somewhat higher in patients with low serum selenium concentrations prior to diagnosis. An inverse association with total cancer risk was found in four prospective studies ${ }^{1-4}$ over a wide range of selenium concentrations. In a five year follow up study Willett et al' observed that the risk of cancer for subjects in the lowest quintile of serum selenium was twice that of subjects in the highest. Salonen et al found a significantly increased risk of cancer among those with serum selenium concentrations of less than $45 \mu \mathrm{g} / \mathrm{l}(0.57 \mu \mathrm{mol} / \mathrm{l})^{2}$ and an adjusted six-fold risk of fatal cancer among subjects in the lowest tertile of selenium concentrations compared with those with higher values. ${ }^{3}$ Subgroup analyses on some of these data do, however, show an effect only in men. ${ }^{13}$ Kok et $a l$ reported that relative risk of death from cancer is 2.7 among men in the lowest quintile compared with those with higher serum selenium concentrations. ${ }^{4}$

We tested the effect of baseline serum selenium concentration on the subsequent risk of cancer in a prospective study in Tromsø, Norway. This population was characterised by intermediate serum selenium concentrations with about $95 \%$ of the subjects having serum selenium values between 1.15 and $2.05 \mu \mathrm{mol} / 1$ $(90.8$ and $161.9 \mu \mathrm{g} / \mathrm{l}){ }^{5}$

Accepted for publication 17 November 1987

\section{Material and methods}

Data from the second Tromsø Heart Study (1979$80),{ }^{6}$ a population survey of cardiovascular risk factors, were used. All men aged between 20 and 54 and women aged between 20 and 49 (21 329 subjects) living in Tromsø were invited; $16621(78 \%)$ participated. ${ }^{6}$ Participants answered a questionnaire nearly identical with that used in the first Tromsø Heart Study ${ }^{7}$ and the cardiovascular studies in the Norwegian counties, ${ }^{8}$ blood pressure, height, and weight were measured and non-fasting blood samples for measurement of total serum cholesterol, high density lipoprotein cholesterol, triglycerides and glucose were taken. An extra blood sample was taken from 9364 patients who attended screening (in 1979). These serum samples were stored in closed plastic tubes at $-20^{\circ} \mathrm{C}$ until use.

Up to the end of 1985 , cancer was diagnosed in 72 of the 9364 participants. All patients had been free of malignant diseases at the time of the first examination in 1979, and were identified by the Norwegian Cancer Registry. Information was derived from clinical, cytological, and histological results, and from necropsy reports, and through death certificates matched against the files of the Central Bureau of Statistics. Only serum samples from 60 patients could be obtained, as serum samples from the other 12 had been used for non-selenium related research purposes. One control case was matched to each of these cases, according to sex, age (within the same year), daily 
consumption of cigarettes (non-smoker , 1-10, 11$20,21-30$, or more than 30 cigarettes a day), month of blood sampling, and place of residence (one of four districts of Tromsø).

Analyses of total serum cholesterol concentrations were performed shortly after screening. The analyses of selenium were performed at the Institute of Occupational Health in Oslo in December 1986, when the serum samples were thawed for the first time.

Selenium concentrations were determined by electrothermal atomic absorption spectroscopy after dilution with a nickel matrix modifier according to the method of Saeed et al. ${ }^{9}$ Specimens from each patient and matched control were randomly grouped into pairs and analysed sequentially in duplicate. Calibration was done against standards based on human serum known to contain selenium. ${ }^{10}$ Quality assurance was ensured using a certified reference serum as a quality control." The coefficient of variation for the reference serum measured for every tenth specimen was $2.4 \%$. The mean (SD) concentration of selenium in the reference serum was $1.16(0.03) \mu \mathrm{mol} / 1(91.6$ $(2.4) \mu \mathrm{g} / \mathrm{l})$, while the proposed concentration was 1.15 $(0.08) \mu \mathrm{mol} / \mathrm{l}(90 \cdot 8(6 \cdot 3) \mu \mathrm{g} / \mathrm{l}) .^{11}$

Statistical analyses were performed using the Statistical Package for the Social Sciences $\left(S P S S^{x}\right) .^{12}$ The mean differences between cases and controls were tested for significance with a $t$ test for paired samples. Selenium values were grouped into quartiles according to the distribution among controls. In a separate set of analyses we disregarded the matching, and multiple logistic regression was used to estimate the effect of serum selenium on cancer risk adjusted for a number of possible confounding variables, such as age, sex, smoking habit, total serum cholesterol concentration, systolic blood pressure, body mass index $\left(\mathrm{kg} / \mathrm{m}^{2}\right)$, and years of education.

\section{Results}

Table 1 identifies the baseline characteristics of the cancer patients and controls. The data indicate that the matching was successful. The distribution of serum selenium concentrations in patients and controls approximated the normal curve, but the median was
Table 1 Baseline characteristics of cancer cases and matched controls (Tromso 1979-80)

\begin{tabular}{lrr}
\hline & \multicolumn{2}{l}{ Mean (SEM) } \\
\cline { 2 - 3 } Characteristics & \multicolumn{1}{l}{ Cases } & \multicolumn{1}{c}{ Controls } \\
\hline Age at examination (years)* & $43 \cdot 0(0 \cdot 9)$ & $42 \cdot 9(0 \cdot 9)$ \\
Cigarettes (No smoked/day)* & $6 \cdot 8(1 \cdot 1)$ & $6 \cdot 2(0 \cdot 9)$ \\
Systolic blood pressure (mmHg) & $132 \cdot 0(2 \cdot 3)$ & $129 \cdot 6(2 \cdot 0)$ \\
Diastolic blood pressure (mmHg) & $84 \cdot 1(1 \cdot 5)$ & $84 \cdot 2(1 \cdot 4)$ \\
Serum cholesterol (mmol/l) & $6 \cdot 1(0 \cdot 1)$ & $6 \cdot 4(0 \cdot 1)$ \\
Body mass index (kg/m $)$ & $23 \cdot 9(0 \cdot 4)$ & $24 \cdot 7(0 \cdot 5)$ \\
Years of education & $9 \cdot 5(0 \cdot 5)$ & $8 \cdot 7(0 \cdot 3)$ \\
Men (\%)* & $43 \cdot 3$ & $43 \cdot 3$ \\
Smokers $(\%)^{*}$ & $53 \cdot 3$ & $53 \cdot 3$ \\
\hline
\end{tabular}

*Matching variables

slightly lower than the mean. The mean difference in serum selenium between cases of cancer and controls was not significant from zero (table 2). The mean difference in serum selenium concentration between cases and controls was about the same in men and women, so we combined the results of the two sexes. Those patients that died had significantly lower serum selenium concentrations than their matched controls $(p<0.01)$ (table 2). As expected, fatal cancers tended to be gastrointestinal (eight of 11), pulmonary (five of seven), and haematological (four of seven).

As preclinical disease may affect selenium concentrations we examined this by comparing the cases diagnosed during the first two years and those diagnosed the succeeding two and the last two years of the follow up period with their controls. Contrary to our expectations, cases diagnosed during the first two years of follow had insignificantly higher serum selenium concentrations than those diagnosed during the two other two year periods. The difference in serum selenium concentrations between cases and controls was similar for the three time periods. This was also true for fatal cancers.

The mean difference in serum selenium concentrations was greatest and significant for haematological cancers alone, though lower concentrations were observed for other cancer sites (table 3).

The Cancer Registry also provides the opportunity to examine selenium concentrations in different his-

Table 2 Mean concentration and difference (and SEM) in baseline serum selenium concentration ( $\mu$ mol/l)* in men and women with all types of cancer, all fatal cancers, and their matched controls (Tromso, 1979-80)

\begin{tabular}{llllll}
\hline & No of pairs & Cases & Controls & Difference & $p$ Value \\
\hline Men & 26 & 1.57 & 1.65 & $0.08(0.04)$ & 0.08 \\
Women & 34 & 1.56 & 1.62 & $0.06(0.06)$ & 0.36 \\
All cancers & 60 & 1.56 & 1.63 & $0.07(0.04)$ & 0.10 \\
Fatal cancers & 25 & 1.54 & 1.69 & $0.14(0.05)$ & 0.01 \\
\hline
\end{tabular}

*Conversion factor: $\mu \mathrm{mol} / 1 \times 78.96=\mu \mathrm{g} / \mathrm{l}$. 
Table 3 Mean concentration and difference (and SEM) in baseline serum selenium concentration ( $\mu$ mol/l)* in 60 cases and their matched controls according to site of cancer (Tromso, 1979-80)

\begin{tabular}{lccccc}
\hline Site of cancer and ICD code & No of pairs & Cases & Controls & Difference & $p$ Value \\
\hline Gastrointestinal (140-159) & 11 & 1.57 & 1.63 & $0.06(0.05)$ & 0.30 \\
Respiratory (160-162) & 7 & 1.57 & 1.71 & $0 \cdot 14(0 \cdot 11)$ & 0.25 \\
Breast (170) & 10 & 1.66 & 1.63 & $-0.03(0 \cdot 13)$ & 0.08 \\
Urogenital (171-181) & 16 & 1.56 & 1.59 & $0.03(0 \cdot 10)$ & $0 \cdot 73$ \\
Haematological (200-209) & 7 & 1.40 & 1.60 & $0 \cdot 20(0.07)$ & $0 \cdot 03$ \\
Other (182-199) & 9 & 1.56 & 1.66 & $0 \cdot 10(0 \cdot 11)$ & 0.40 \\
\hline
\end{tabular}

ICD = International Classification of Diseases, Seventh Revision.

*Conversion factor: $\mu \mathrm{mol} / 1 \times 78.96=\mu \mathrm{g} / 1$.

tological groups. ${ }^{1314}$ As the case numbers were small, the only conclusion that can be drawn is that low serum selenium concentration does not seem to be associated with increased risk of development of adenocarcinoma. There were 26 cases of adenocarcinoma and the difference between cases and controls was $0.02 \mu \mathrm{mol} / \mathrm{l} \quad(1.6 \mu \mathrm{g} / \mathrm{l}), \quad 95 \% \quad$ confidence interval $=-0 \cdot 10$ to $0.14 \mu \mathrm{mol} / 1$.

The relative risk for cancer in the lowest quartile $(<1.45 \mu \mathrm{mol} / 1 \quad(114.5 \mu \mathrm{g} / \mathrm{l}))$ of serum selenium concentration was 1.4 compared with higher serum selenium concentration $(95 \%$ confidence interval $=0.6-3.5$ ). The estimate of relative risk was not changed significantly when the data were analysed without taking the matching into consideration and when adjusted by multiple logistic regression for the potential confounders of sex, age, smoking habit, total serum cholesterol concentration, systolic blood pressure, body mass index, and length of education.

\section{Discussion}

Our findings show that although serum selenium concentration was lower in cancer patients before diagnosis than it was in matched controls for most cancer sites, this was only significant for leukaemia. In agreement with a recent report, ${ }^{15}$ we did not find any indications of a positive correlation between low serum selenium concentration and risk of breast cancer, nor did we find a significant difference for lung cancer, but there were only seven cases of lung cancer and the mean difference in serum selenium between these cases and controls was substantial $(0.14 \mu \mathrm{mol} / \mathrm{l})$ $(11 \cdot 1 \mu \mathrm{g} / \mathrm{l}) .^{1617}$

Considering that cancer is a heterogeneous group of diseases with different aetiologies, the possible protective effect of selenium may be more important for some cancers than for others. This may explain the findings in some studies which show that low serum selenium concentration protects against cancer in men but not in women. ${ }^{134}$ The significant difference in serum selenium between patients who died and their matched controls may indicate that high selenium concentrations protect against certain cancers with a poor prognosis. Though there is some support for the present observations, ${ }^{23}$ the possibility that the significant differences seen for fatal and haematological cancers may be the result of chance, can not be excluded.

Few studies have examined serum selenium concentration in cancers of different histological groups. This is important when the aetiological relevance of selenium in carcinogenesis is considered. Though the interpretation of our findings was hampered by a small number of cases, the results indicate that serum selenium has no bearing on the risk of adenocarcinoma ( $43 \%$ of the cancers in this study).

The difference between serum selenium concentrations in patients and controls was not significant in either men or women, but the $p$ value for all cases was not very high $(p=0 \cdot 10)$ and the mean difference between cases and controls $(0.07 \mu \mathrm{mol} / 1(5.5 \mu \mathrm{g} / \mathrm{l})) \mathrm{did}$ not differ greatly from the difference found in other prospective studies $(0.09-0.13 \mu \mathrm{mol} / 1(7 \cdot 1-10.3 \mu \mathrm{g} /$ 1)). ${ }^{1-4}$ The insignificant difference in serum selenium between cases and controls for all cancers or some cancer sites (lung cancers) may, therefore, to some extent be due to lack of statistical power.

Stored sera from $12(17 \%)$ of the cancer patients could not be analysed as they had been used for other research purposes. This underlines the need for the storage of several frozen serum aliquots.

The mechanisms proposed for anticarcinogenic effect of selenium include protection from oxidative damage from carcinogens, effects on carcinogen metabolism, and reduction in mutagenecity and toxicities of selenium metabolites to proliferating cells. ${ }^{1819}$ As the activity of the selenium dependent enzyme glutathione peroxidase tends to level out above selenium concentrations of $1.3 \mu \mathrm{mol} / 1(102.6 \mu \mathrm{g} / \mathrm{l})$ in whole blood, ${ }^{20}$ this may explain the stronger dose-response association between selenium and risk of cancer as seen in Finland, where the mean serum selenium concentration is lower than in Norway. ${ }^{21}$

The results from epidemiological studies have been inconclusive, and we still do not know whether increasing the intake of selenium reduces the risk of 
cancer in man. In future we advocate that less emphasis should be put on associations with total cancer incidence and that more emphasis should be placed on the associations between serum selenium and different types of cancers, both with regard to site and histological type. Trials of chemoprevention may provide definitive information on the possible anticarcinogenic effect of selenium, but such trials are difficult to perform as we do not know the optimal concentration of selenium supplement to be used, and because people have to be followed up long term.

This study was supported by the Norwegian Research Council for Science and the Humanities.

\section{References}

I Willett WC, Polk BF, Morris JS, et al. Prediagnostic serum selenium and risk of cancer. Lancet 1983;ii:130-4.

2 Salonen JT, Alfthan G, Huttunen JK, Puska P. Association between serum selenium and the risk of cancer. Am J Epidemiol 1984;120:342-9.

3 Salonen JT, Salonen R, Lappetelainen R, et al. Risk of cancer in relation to serum concentrations of selenium and vitamins $A$ and $\mathrm{E}$ : matched case-control analysis of prospective data. $\mathrm{Br}$ Med J 1985; 290:417-20.

4 Kok FJ, De Bruijn AM, Hofman A, Vermeeren R, Valkenburg HA. Is serum selenium a risk factor for cancer in men only? $\mathrm{Am} \mathrm{J}$ Epidemiol 1987;125:12-6.

5 Ringstad J, Jacobsen BK, Thomassen Y. The Tromsø Heart Study: relationships between the concentration of selenium in serum and risk factors for coronary heart disease. Journal of Trace Elements and Electrolytes in Health and Disease 1987; i:27-31.

6 Thelle DS, Arnesen E, Førde OH. The Tromsø Heart Study: does coffee raise serum cholesterol? N Engl J Med 1983; 308:1454-7.

7 Thelle DS, Førde OH, Try K, Lehmann EH. The Tromsø Heart Study: methods and main results of the cross-sectional study. Acta Med Scand 1976;200:107-18.
8 Bjartveit K, Foss OP, Gjervig T, Lund-Larsen PG. The cardiovascular disease study in Norwegian counties. Acta Med Scand 1979;(suppl 634): 1-70.

9 Saeed K, Thomassen Y, Langmyhr FJ. Direct electrothermal atomic absorption spectrometric determination of selenium in serum. Anal Chim Acta 1979;110:285-9.

10 Ihnat M, Wolynetz MS, Thomasssen Y, Verlinden $M$. Interlaboratory trial on the determination of total selenium in lyophilized human blood serum. Pure Applied Chemistry 1986;58:1063-76.

11 Ihnat M, Thomassen Y, Wolynetz MS, Veillon C. Trace element data reliability in clinical chemistry - interlaboratory trials and reference materials. Acta Pharmacol Toxicol 1986;59(suppl VII):566-72.

12 SPSS $^{x}$. User's guide. 2nd ed. New York: McGraw-Hill, 1986.

13 Task-force to revise the manual of tumor nomenclature and coding, (Motnac). Washington, DC: American Cancer Society, 1968.

14 Systematized nomenclature of pathology (SNOP). Chicago: College of American Pathologists, 1965.

15 Meyer F, Verreault R. Erythrocyte selenium and breast cancer risk. Am J Epidemiol 1987;125:917-9.

16 Menkes MS, Comstock GW, Vuilleumier JP, Helsing KJ, Rider AA, Brookmeyer R. Serum beta-carotene, vitamins A and E, selenium and the risk of lung cancer. $N$ Engl $J$ Med 1986;315:1250-4.

17 Nomura A, Heilbrun LK, Morris JS, Stemmermann GN. Serum selenium and risk of cancer, by specific sites: Case-control analysis of prospective data. JNCI 1987;79:103-8.

18 Combs GF, Clark LC. Can dietary selenium modify cancer risk? Nutr Rev 1985;43:325-31.

19 Vernie LN. Selenium in carcinogenesis. Biochim Biophys Acta 1984;738:203-17.

20 Thomson CD, Rea HM, Doesburg VM, Robinson MF. Selenium concentrations and glutathione peroxidase activities in whole blood of New Zealand residents. Br J Nutr 1977;37:457-60.

21 Westermarck T, Raunu P, Kirjarinta M, Lappalainen L. Selenium content of whole blood and serum in adults and children of different ages from different parts of Finland. Acta Pharmacol Toxicol 1977;40:465-75.

Requests for reprints to: Dr J Ringstad, Institute of Community Medicine, University of Tromsø, PO Box 417, N9001 Tromsø, Norway. 